\title{
A Traceless Capping for Agent Peptide Sequencing by Partial Edman Degradation and Mass Spectrometry
}

Amit Thakkar, Anne-Sophie Wavreille, and Dehua Pei*

\section{(Supporting Information)}

Figure S1. MALDI-TOF MS spectra of 20 beads from a pY-containing peptide library, AXXpYXXXLNEBBRM, synthesized on $90 \mu \mathrm{m}$ TentaGel S $\mathrm{NH}_{2}$ resin (trial \#8 in Table 1). PED was performed at 20:1 PITC/Fmoc-OSU ratio. $B, \beta$-alanine; $C$, 2-aminobutyrate; $M$, methionine at $C$-terminus or norleucine at internal positions. 

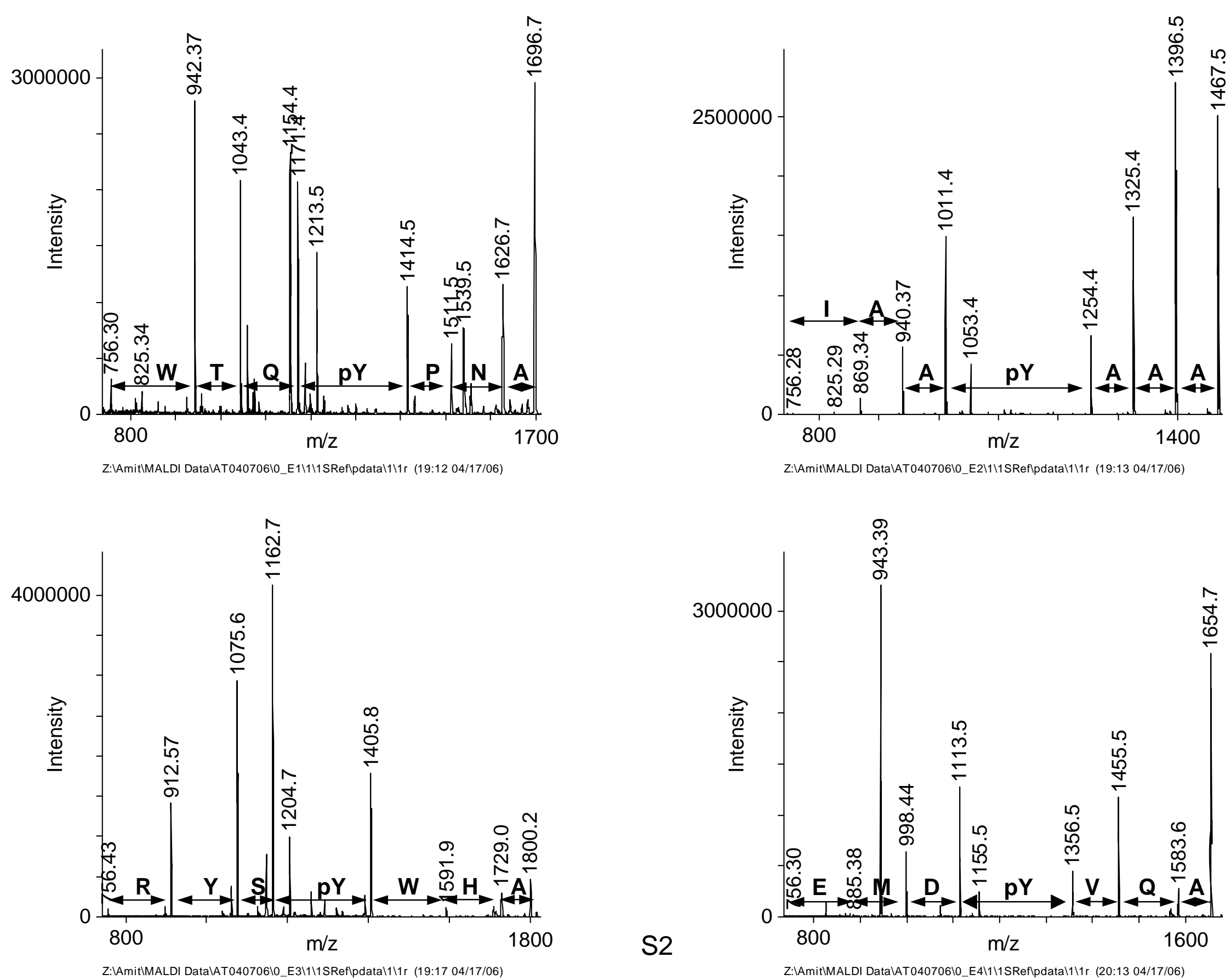

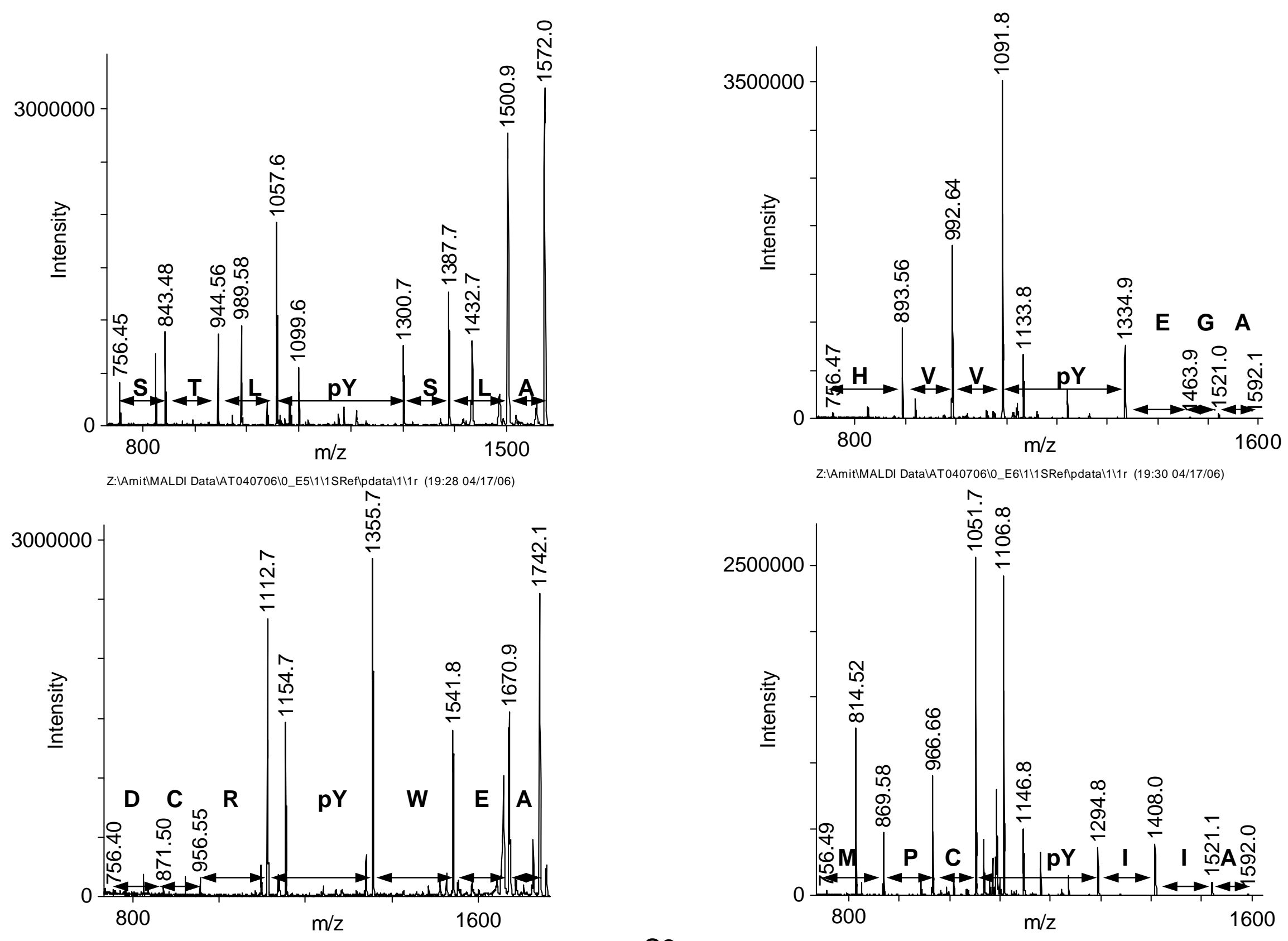

Z:IAmitIMALDI DatalAT04070610_E7|111SReflpdatal111r (20:41 04/17/06)

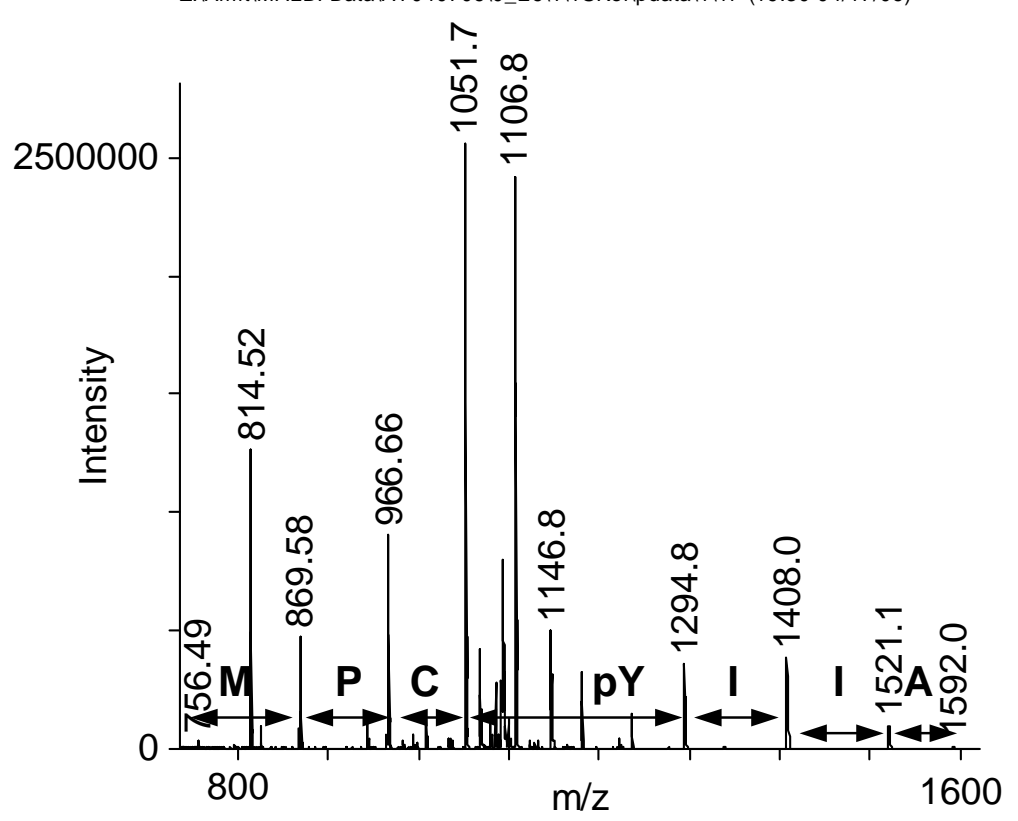

Z:IAmitlMALDI DatalAT04070610_E81111SReflpdatal111r (19:37 04/17/06) 


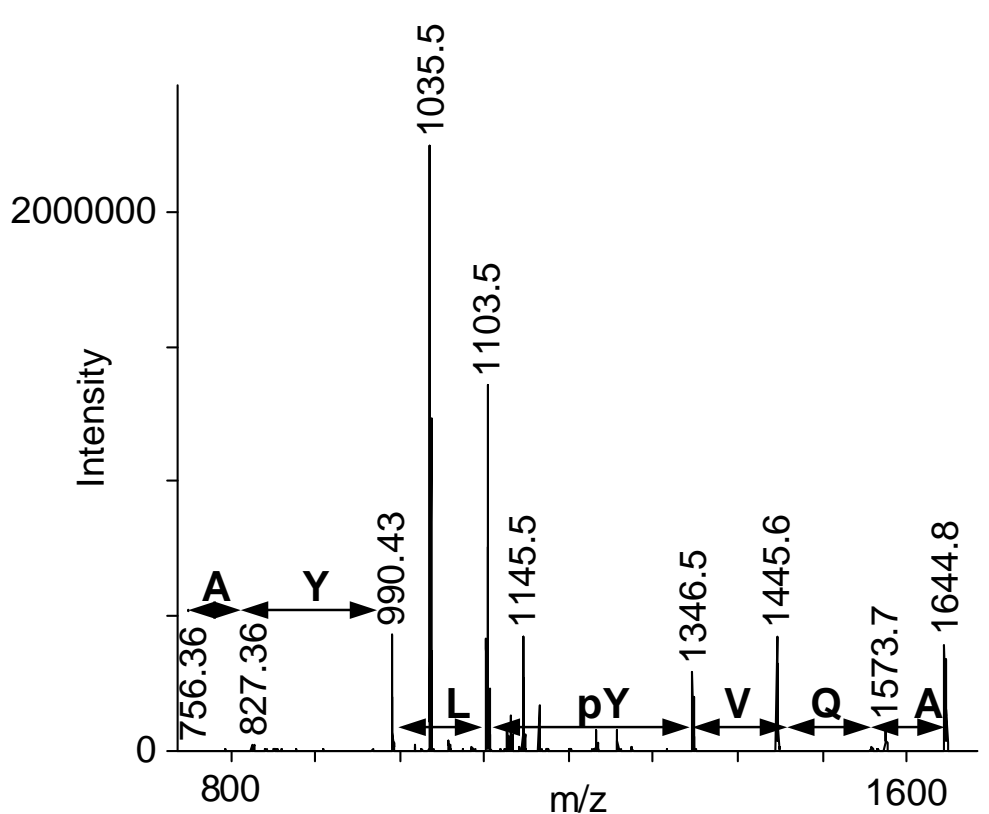

Z:IAmitIMALDI DatalAT04070610 E91111SReflpdatal111r (19:41 04/17/06)

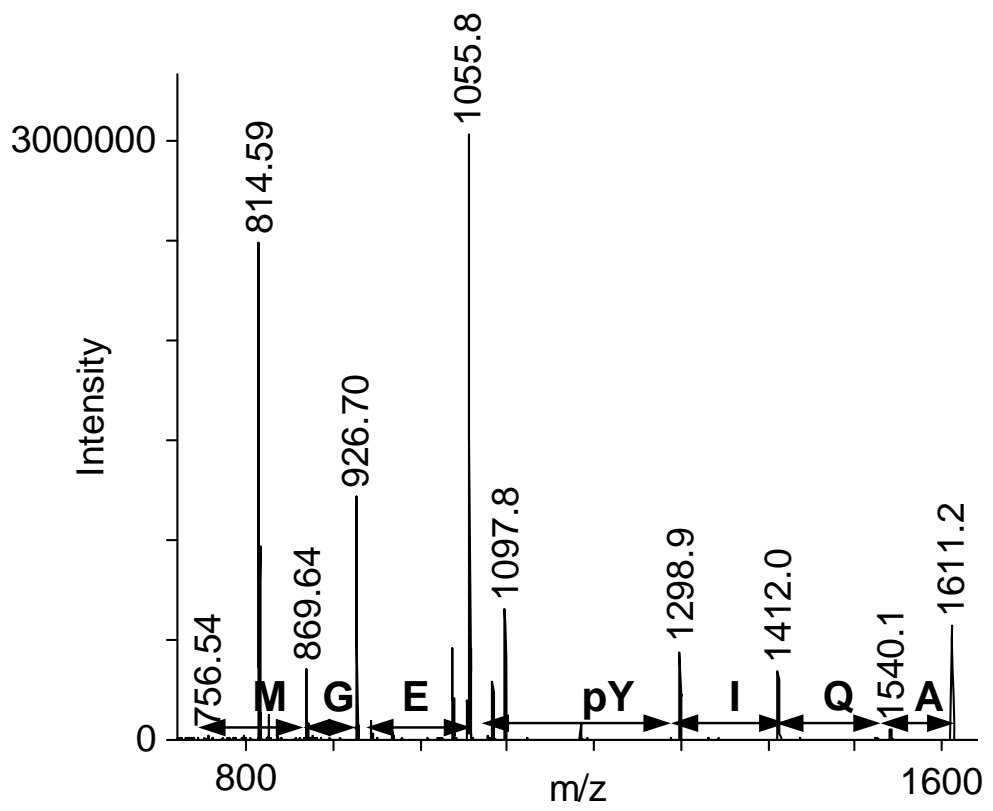

Z:IAmitIMALDI DatalAT04070610 E11|111SReflpdatal111r (20:52 04/17/06)
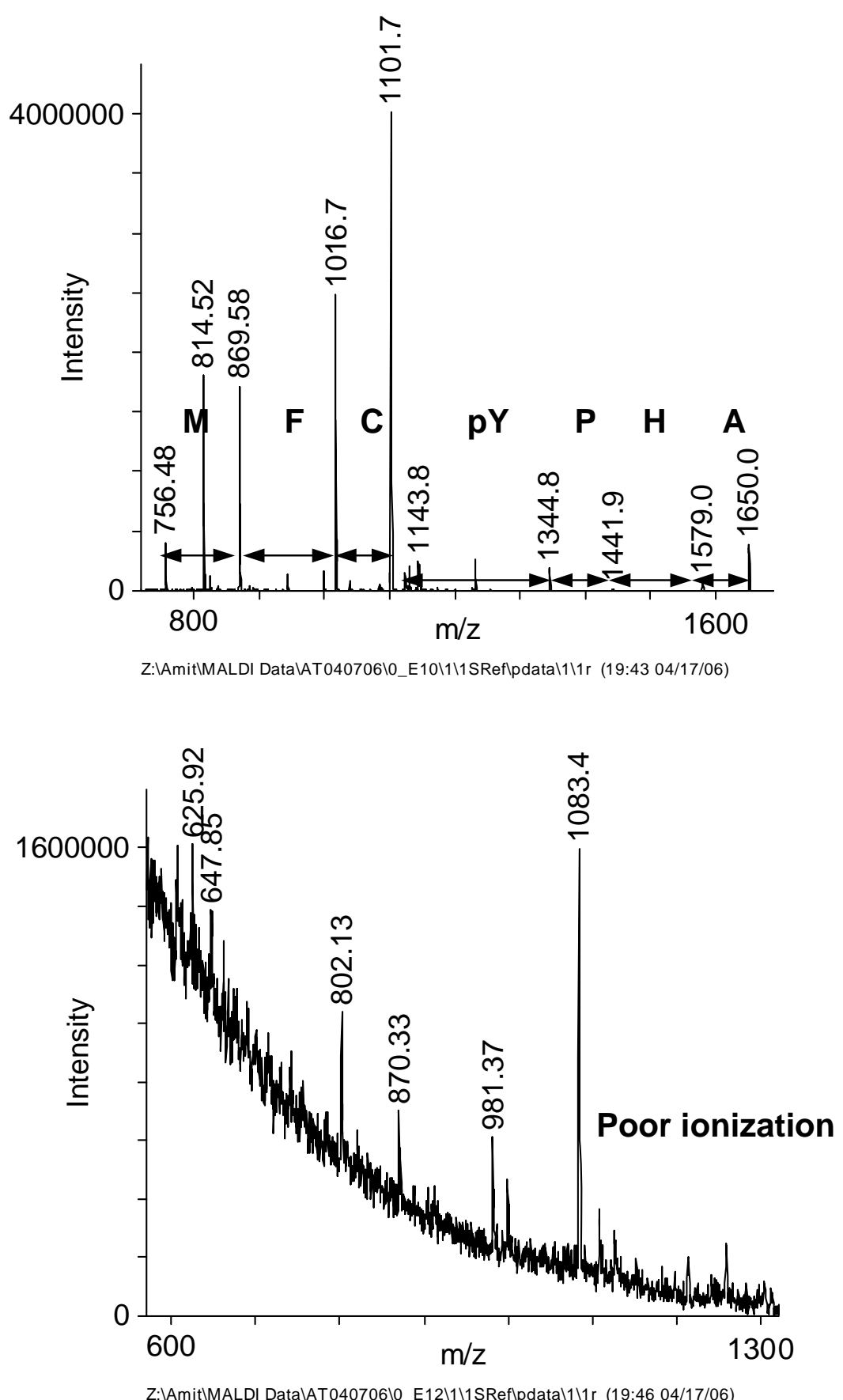

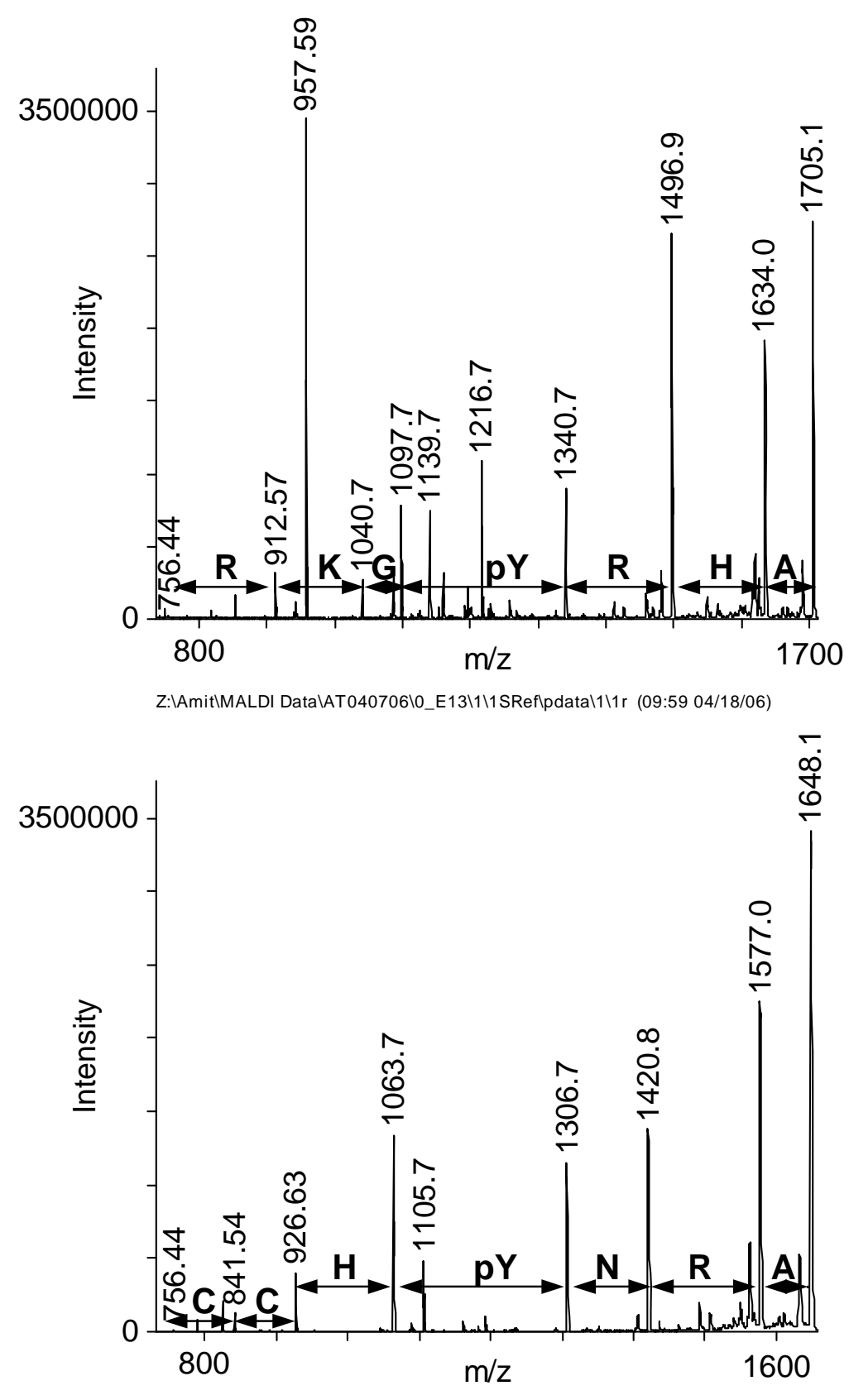

Z:IAmitIMALDI DatalAT04070610_E15|111SReflpdatal111r (10:05 04/18/06)
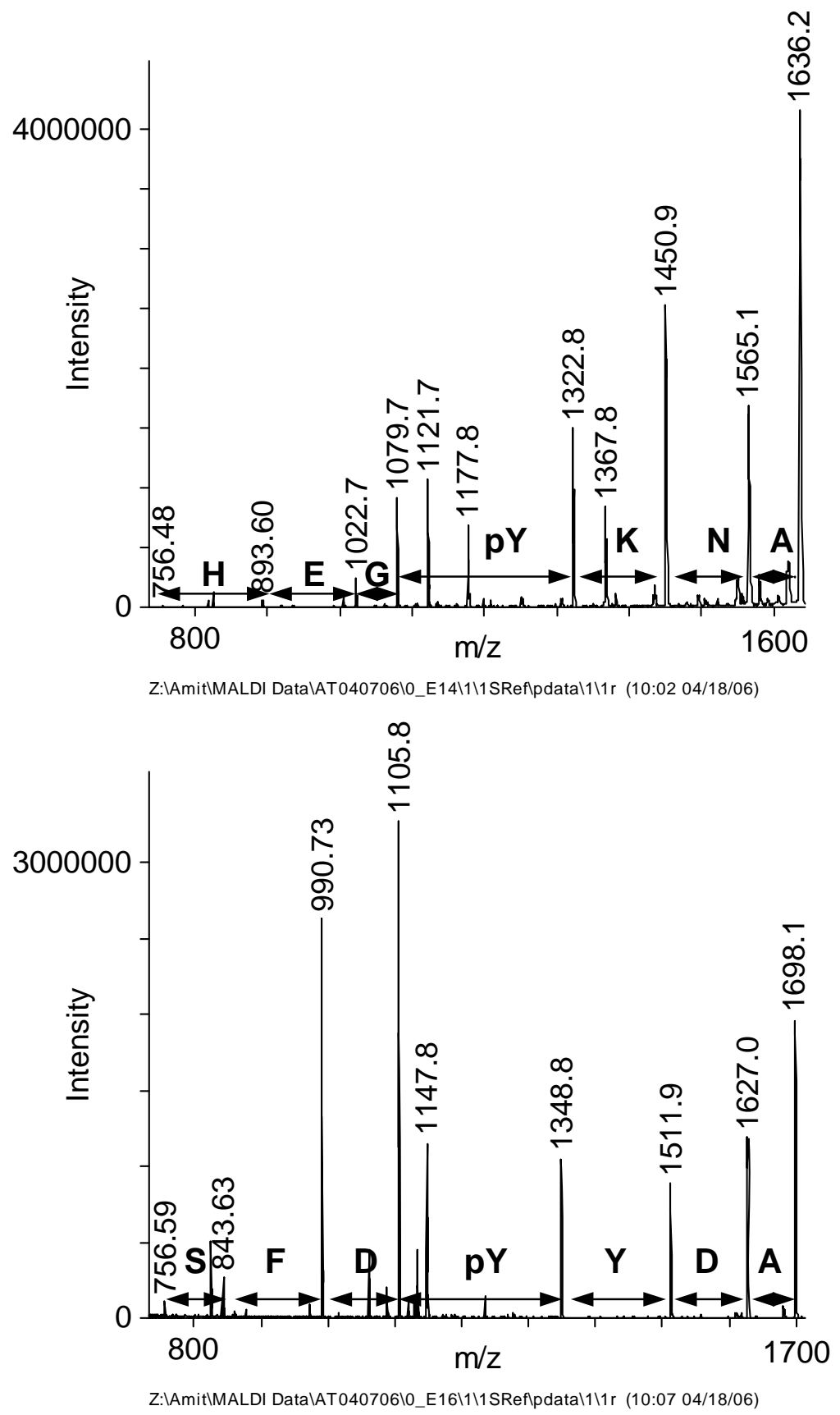


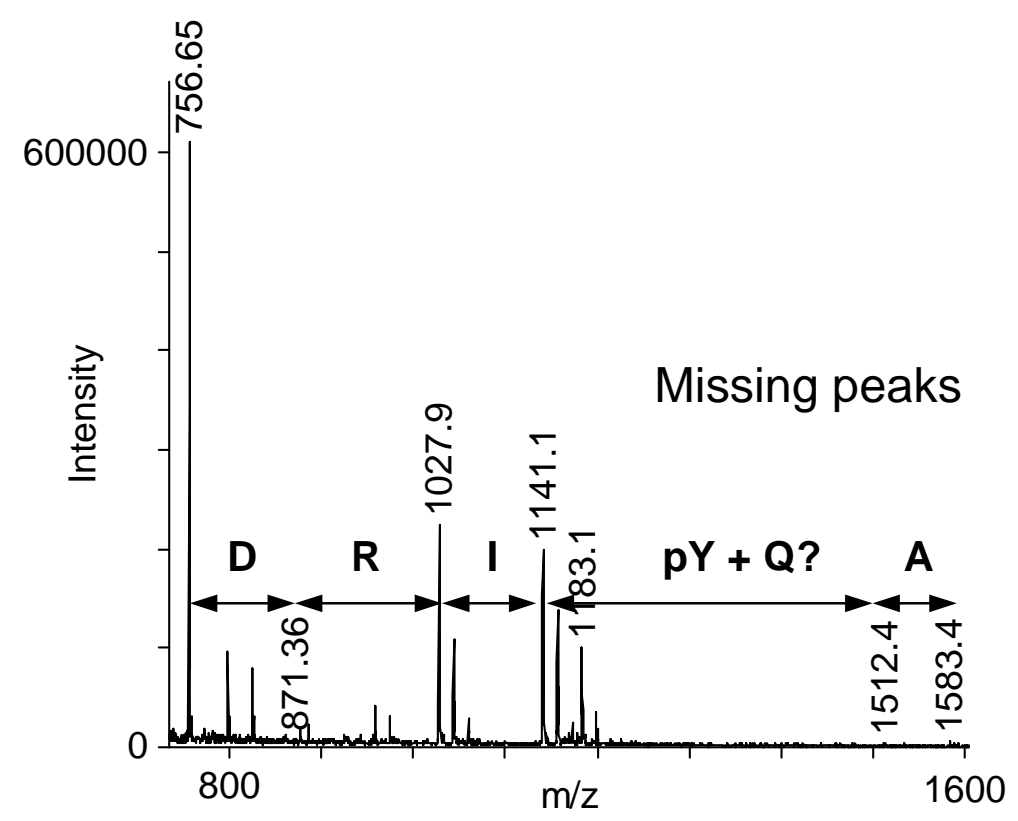

Z:IAmitIMALDI DatalAT04070610_E171111SReflpdatal111r (10:12 04/18/06)

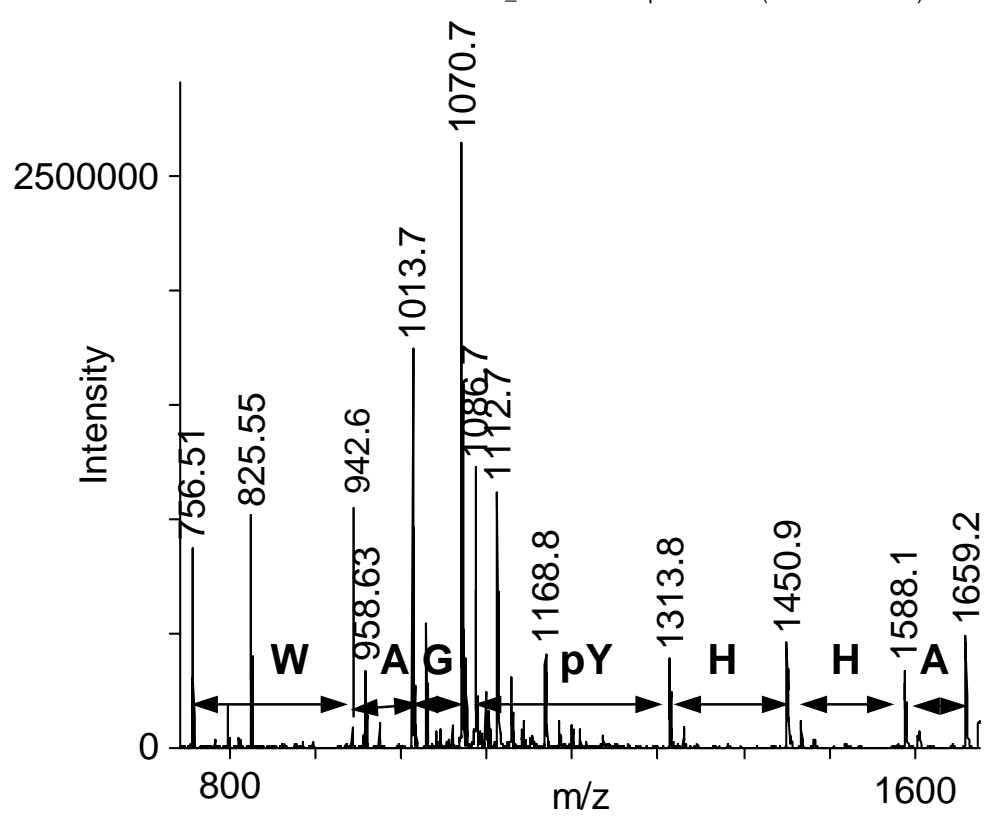

Z:IAmitIMALDI DatalAT04070610_E191111SReflpdatal111r (10:18 04/18/06)

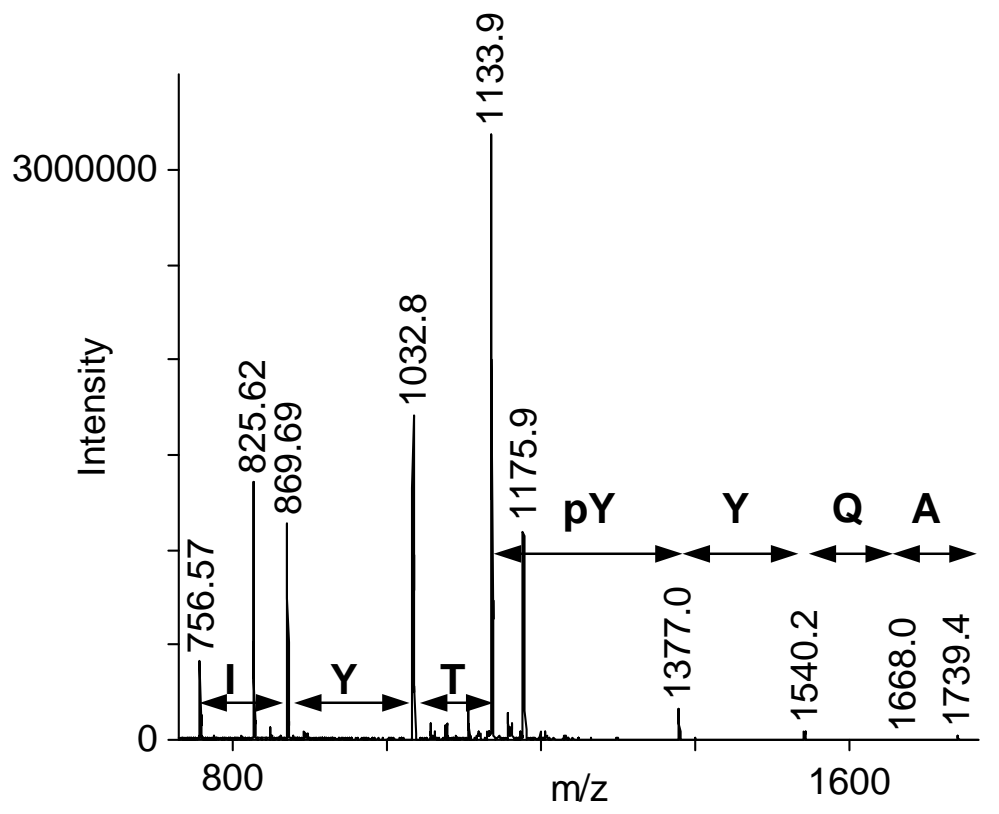

Z:IAmitIMALDI DatalAT04070610_E18|111SReflpdatal111r (10:16 04/18/06)

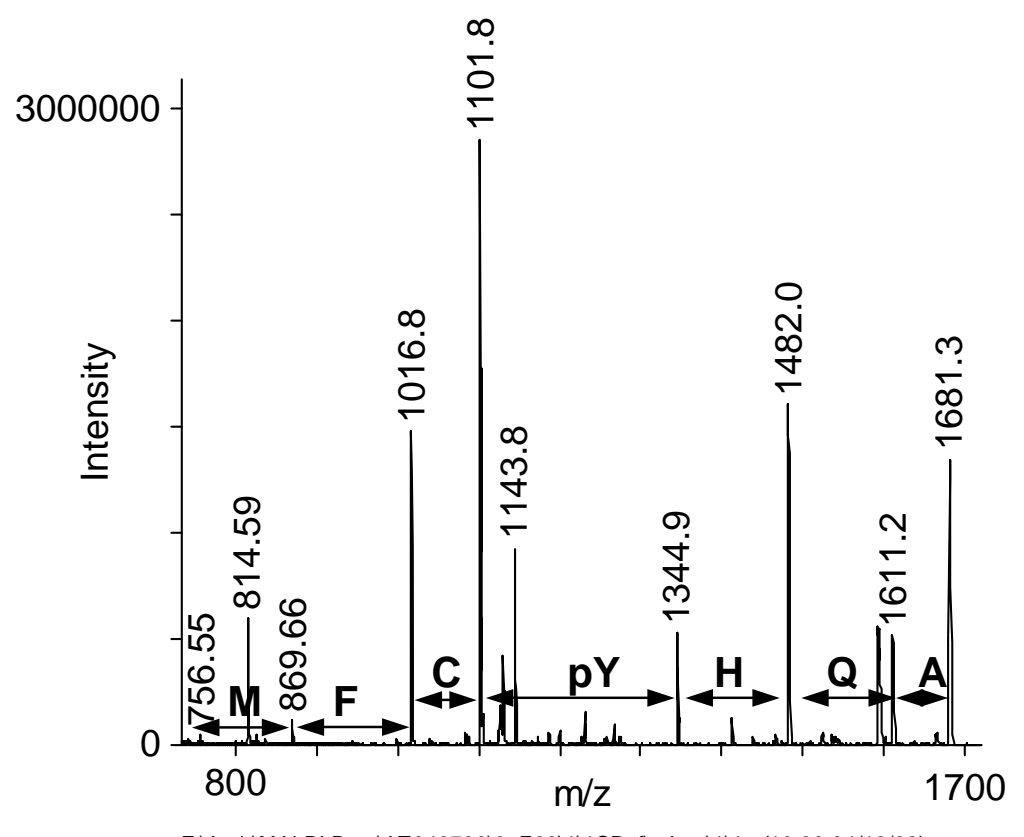

Z:IAmitIMALDI DatalAT04070610_E201111SReflpdatal111r (10:20 04/18/06) 